\title{
DIALOGIC SIGNALS IN ARGUMENTATIVE DISCUSSIONS OF ADVANCED POLISH LEARNERS OF ENGLISH*
}

\author{
AGNIESZKA NOWICKA \\ Adam Mickiewicz University - Poznan
}

\begin{abstract}
The first part of the paper deals with characteristics of classroom interaction as a type of institutional talk in a conversational analytic perspective. Next, the thesis is discussed concerning developing learners' interactional competence to foster learner discursive independence in argumentative discussions in English as a foreign language. Finally, after a short review of dialogic signals, the article presents a preliminary analysis of selected dialogic signals: evaluating reformulations and piggybacking as the ways of achieving reciprocity in argumentative discussions.
\end{abstract}

\section{Introduction}

The article' presents a thesis concerning the process of learning dialogic signals by advanced Polish learners of English in argumentative discussions. The main focus of the article is a discussion of the significance of dialogic signals in developing interactional competence and its most important aspect: the strategic control of the interaction. The article gives a preliminary report on the recipient design and the use of dialogic signals by advanced and upper intermediate Polish students of English. The study was conducted within a larger group project researching the development of learner autonomy and, specifically, learners' individual communicative competence (Wilczyńska 2001, 2002).

\section{School Interactions and Learners' Didactic and Discursive Dependency}

Conversation Analysis treats the foreign language classroom discourse as a variety of institutional talk, which is established by the community of practice or the community created for institutional purposes. The main feature of such institu-

\footnotetext{
* This is a corrected version of the article published in Glottodidactica XXIX.

' I would like to acknowledge Professor Weronika Wilczyńska for inspiring methodological comments on this article.
} 
tional talk is its orientation to certain educational aims, to specific types of tasks and identities characteristic of a given institution (Seedhouse 1996:151; Silverman 1998:165). School interactions in a foreign language constitute a specific institutional type of the interaction in which:

- teachers evaluate linguistic forms and patterns of interaction produced by a student;

- language is not only a vehicle but also the object of learning;

- didactic aims, to a large extent, shape the linguistic forms and patterns of classroom interaction;

- participants of the interaction orient to specific institutional aims;

- specific types of inferencing and reasoning take place (Seedhouse 1996:151; Silverman 1998:166-167).

In the university context, participants of the interaction appear in specifically preordained social and interactional roles, mainly of a student or a teacher of a foreign language. From the conversational analytic perspective, participants of the talk-in-interaction construe themselves in those roles when they undertake certain verbal actions and interpret the utterances of their coparticipants by referring to commonsensical knowledge of the world and social conduct. They participate in classroom talk referring to a specific asymmetrical participation framework which curtails their use of language to a limited set of actions.

The prevailing pattern of interaction emerging from observations of teacherfronted discussions reveals, on the one hand, deep communicative dependency of students on teachers and on the other, the orientation of both teachers and students to a certain vision of what a classroom discussion and thus also a foreign language class should look like. Reducing its participants to the function of the external and determining social context, such formulas of interaction prevent students from developing the interactive and personal use of the language understood as the constituent skill in learner's communicative competence.

Communicative competence, in its individual and personal dimension, consists of knowledge and communicative skills allowing the learner to function in a foreign language in an authentic way that is in accordance with their life goals and personality (Wilczyńska 1999). One needs not add that in most traditional and teacher-fronted school interactions this individual dimension, as opposed to the institutional one, plays rather an insignificant role.

The article will focus on interactional aspects of communicative competence observed as specific interactive behavior of learners in the situated context of argumentative discussions in English as a foreign language.

\subsection{Superficial versus Deep Interactivity}

Researchers have observed that during classroom discussions in a foreign language, students rely primarily on teachers to direct the discussion by controlling 
its thematic progression, allocating turns of speaking and evaluating ongoing students' discourse.

The pilot study, conducted within the above mentioned research project (Prokop 2001), confirms those observations since, in the majority of classroom dialogs in a foreign language, the teacher is the primary sender and addressee of talk, while only a relatively small number of interactions is directed by students towards other students. Apart from that, the range of actions undertaken by students in school interactions in a foreign language is somewhat limited; students for example find out new information from their interlocutors using only direct questions, the behavior only rarely appearing out of the classroom context in ordinary conversations (Prokop 1995). The formality and artificiality of classroom communication is connected with its narrow focus on purely informational exchanges while disregarding the expressive function of the language. Students and teachers commonly produce their classroom talk with a great degree of formality, distance and asymmetry due to their unreflective or conservative orientation to educational aims, values and their roles in the educational process.

Markee observed that learners act within or refer to an unequal power speech exchange system. Teachers in such a system typically ask more display questions to which they already know the answer; while referential or new information questions, asked relatively rarely in teacher student exchanges, would incite learners to produce syntactically more complex and connected answers. Such an exchange system thus creates a very limiting acquisitional environment for learners (Markee 2000:64-77). Markee, however, claims such inequality to be primarily the feature of teacher-student interactions. This inequality can be explained by a traditional vision of education which frames the teacher as the examiner and transmitter of knowledge to the student. In contrast, as Markee observes, student to student or small group environments automatically create an equal exchange system in which those differences or features of classroom talk seem to disappear.

It is true that the change of participation framework to a large extent influences the actions of participants. However, as preliminary analysis of classroom interactions reveals (Górecka and Nowicka 2001), the change happens only superficially because even in the small group context students often behave as if the teacher were present and steering their discussion. In other words, they indirectly aim their utterances at the institutional recipient while disregarding the "here and now" present interactional partner.

One of the prevailing modes of the discussion in a foreign language classroom is so-called triadic argumentation during which students either directly or indirectly filter their talk through the teacher for the monitoring of the content and/or form of the utterance. The teacher functions as a specific kind of institutional evaluator in a type of examinational discourse, and the student as the interviewee, neither fully engaging in expressing personal attitudes towards the subject or the interlocutor. 
Thus the most striking feature of such learner talk is its low degree of interactivity appearing in the relatively small number of not only dialogic signals but also the signals structuring and monitoring the ongoing dialogs. Students, in their didactically dependent roles, rely on the teacher to structure or evaluate their utterances. In consequence, even though often seemingly oriented to other student participants, their dialogs lack interactive orientation and often aim rather at the grammatical correctness and verbal and syntactic sophistication of a memorized written discourse.

There exists a specific type of the recipient design in school dialogs; the design allows for student's discursive dependency and enhances teacher's dominance. The main recipient of such discourse seems to be the examining institutional controller, a role to be assumed by the teacher. Since the recipient is more virtual and institutional than real and immediate, argumentation assumes the form of a series of loosely connected speeches resembling a peculiar combination of an exam and a formal interview. Even during student to student small group discussions, student utterances are to some extent marked by the absence of teacher's monitoring or by expecting that constant regulations provided by an outer controlling agent will combine monologic texts into a coherent dialog. Even though student to student dialogs sometimes show certain very formal and perfunctory interactivity, it becomes apparent that speakers generally fail to take into account possible recipient's reactions. Recipients, on the other hand, often produce only very few verbal and nonverbal listening signals and as a result of such orientation, speakers' utterances, in extreme cases, hardly ever converge to negotiate a common consensus or aim. The reasons of such situation seem to be:

- the already mentioned orientation to the stereotypical school roles allowing for the low level of personal involvement,

- the absence of a consistently and collaboratively realized communicative aim,

- immature or underdeveloped interactional competence, the unwillingness and/or inability to steer the dialog by using interactionally oriented signals and strategies.

As it has already been pointed out, the institutional context to a large extent influences learners' and teachers' behavior. However, from the ethnomethodological perspective the institutional features of context such as roles or tasks do not determine the type of talk used by speakers. Participants in the interaction actively orient to those roles, aims and tasks by performing only specific types of communicative acts and refraining from performing those which are not associated with the established interactive order. As a result of this process, even teachers who do not aim to teach derivatively or to dominate classroom discussions often get framed in directive roles by their students' orientation.

In contrast to more deterministic sociological views of interaction, conversational analytic understanding of the interaction opens up the space for observing social actions as created locally by its participants. 
Interlocutors create their specific teachers' and students' roles in the course of verbal exchanges, for example by referring to their interlocutors in certain roles. Even though such micro actions in the talk-in-interaction in a native language often happen automatically and beyond speaker's conscious control, learners' focus on their conscious and strategic usage may be the first step to improving interactivity of talk in classroom discussions.

\subsection{Interactional Competence and Dialogic Signals}

In light of the above discussed observations, in the framework of the larger aim of developing learner autonomy, there emerges an important didactic subgoal of developing learner interactional competence in a foreign language. Goodwin (1995:202) defines interactional competence as a speaker's ability to produce sentences that receive appropriate listeners' attention. Repairs prove to be one of the basic forms of the realization of participants' interactive orientation because, as Goodwin observes, they demonstrate a speaker's competence to maintain the social structure of the interaction and to orient to it as the appropriate participation of both the speaker and the listener.

Consequently, the interactional competence comes down to a participants' ability to continually modify the meaning of their utterance so as to initiate the reciprocal changes of the states of knowledge proposed for both the speaker and the recipient.

Interactional or dialogic signals would thus have an effect of maintaining a complementary distribution of knowledge between the participants in interaction. Interactional utterances can be defined as communication strategies (Wilczyńska 1999:81), in particular regulatory strategies, more or less explicit actions by which speakers try to influence the course of the conversation so as to improve their understanding of the co-speaker's talk. The main role of dialogic signals is regulating the course of the conversation and maintaining interactivity geared at the social aim of sustaining contact and relationship between speakers.

In institutional interactions, the concept of interactional competence, while preserving certain universal features relevant for conversations, extends to additional skills which become valid for specific institutional interactions including argumentative discussions. Since institutional talk constitutes a deviation from the primary conversational form, such competence in institutional talk does not seem to be self-evident even in the case of native speakers and has to be consciously developed for various institutional genres. 


\section{Developing Interactional Competence in Argumentative Discussions in English as a Foreign Language}

As has been pointed out, institutional classroom talk frequently enhances the discursive dependency of students; therefore in order to increase interactional competence, one has to change the constituent factors which determine institutionality of talk, namely the participation framework of classroom discussions and the ensuing roles.

\subsection{Design of Argumentative Discussions}

Interactional competence in argumentation realizes itself in the ability of interlocutors to co-construe the speech genre of the argumentative dialog. Argumentation by definition is driven by the social and cognitive divergence of opinions and attitudes. Thus the main didactic aim becomes designing the discussion as a cooperative argumentation oriented towards the coordinated construction of the social and cognitive conflict in observable interactive negotiations of roles, aims, opinions and attitudes. Consequently, classroom dialogs in the project have been designed in such a way so as to incite emotional and intellectual involvement and increase in this way the contact and cooperation between the speakers. To simulate such a social and cognitive conflict, students assume divergent interactional roles of argumentative opponents and supporters to engage in the coordinated regulation of conflicting opinions and the construction of arguments organized around a controversial thesis. In this way, learner interactional competence could be evaluated by their ability to simultaneously construe such a conflict and maintain interpersonal contact without threatening their own or interlocutor's face.

\subsection{Preliminary Analysis of Dialogic Signals and the Recipient Design in an Argumentative Discussion in English as a Foreign Language}

In argumentative discussions, speakers have to engage in the construction of dispreferred parts of adjacency pairs. The "depth" of their interactional involvement appears in their usage of specific dialogic signals and signals structuring their utterances to negotiate their interactional consensus both as a speaker and a listener, either aligning or arguing with their interactional partners.

Participants in ordinary conversations or argumentations, in their native as well as a foreign language achieve reciprocity of perspectives using certain types of signals which can be divided into various classes in different kinds of sequential contexts and taking into account different although mutually interconnected actions such as pursuing a recipient's response in disagreements, controlling the topic organization and the like. 


\subsection{Dialogic Signals}

Agreeing and affiliating, as well as disagreeing and disaffiliating, constitute two main directions of actions undertaken by participants during such discussions. One can distinguish certain genre creating moves functioning as the ways of establishing reciprocity in argumentative discussions. Gülisch and Kotschi (1995) point out that moves in argumentation manifest participant's cognitive control over the discussion. The presence of certain discursive traces of cognitive control or cognitive processing defines discourse as argumentative. However, the cognitive control aspect of those moves does not suffice to classify them as a part of interactional competence. Speakers can exercise impressive cognitive control over their own utterances and still produce disjointed and only superficially coherent dialogs. Interactionally oriented cognitive control must be based both on immediate interactional processing of co-debaters' contributions and on predicting their possible responses. Gülisch and Kotschi (1995:30-66) as well as Basturkmen (1998) distinguish three main procedures driving oral argumentations:

- qualifying procedures which evaluate and comment upon the ongoing dialog. They are often defined as metastatements (Basturkmen 1998),

- treatment procedures such as: reformulations that can be divided into paraphrastic ones (repetitions and paraphrases) and non-paraphrastic ones (dissociations and corrections),

- grounding: hypothesizing and displaying rationale for talking (Basturkmen 1998).

However, the above mentioned procedures alone do not suffice to construe reciprocity; they have to be correlated with an important conversational aspect of the argumentation, that is the aspect oriented at maintaining the relationship between speakers. The reciprocity design in argumentation has a dualistic nature originating from the fact that, as Sacks (1984:21-28) claims, institutional genres are secondary with respect to conversations. Thus, in order to create a well developed and deeper reciprocity design in argumentations, there is a need for participants to combine in their actions two simultaneous directions of referring to ideas and to personalized interlocutors. Using conversational dialogic signals while construing argumentative procedures, speakers manage to maintain personal contact with the interlocutor and attain deeper intersubjectivity. Without this conversational engagement in argumentative discussions, debaters' contributions risk disintegration into a collection of utterances or fossilize in its institutional form of conversational and didactic dependency on the institution and its representatives.

Conversation Analytic research divides dialogic signals into listener's or recipient's signals and speaker's signals appearing in a variety of sequential positions. Besides, on the whole, actions can be defined as preferred and dispreferred ones as in agreements and disagreements. Except for cases of self-criticism, 
agreements are usually preferred reactions, while disagreements are dispreferred ones and require additional face work mainly realized in delays and prefaces expressing indirectness and participant's treatment of disagreement as a potentially face-threatening action.

\section{Construing Reciprocity in Learners' Argumentative Discussion. A Few Examples}

\subsection{A Review of Dialogic Signals}

Researchers analyze verbal dialogic signals as performing two main actions of affiliation and disagreement:

\section{Affiliation or acceptance signals}

- siding with the speaker, agreeing in a reaction to the story;

- turn initial signals of weak agreement: $h m$, uh huh, yeah;

- upgrades or upgraded evaluations (Pomerantz 1984a:57-102; Schegloff 1984:28-53).

\section{Disagreement signals}

- Rejection signals, prefaces or presequences to disagreements or weak disagreements: uh, well, I know but, yes but, so appearing usually initially in the turn to delay the rejection, used to save one's or interlocutor's face and minimize conflict (Schegloff 1984);

- reportings as indirect rejections of speaker's suggestions, indirect ones such as reports realized as avoiding official taking of a position (Schegloff 1984);

- silence, prolonged pauses functioning as other repair initiators (Schegloff 1984);

- downgrades or downgraded evaluations (Pomerantz 1984a);

- latching as a cooperation sign;

- partial repeats as disagreements of partner's utterance (Heritage 1984) also called represents (House 1982);

- partial repeats in the question form did you?

- partial repeats in a statement form you did? (Heritage 1984:299-346);

- pursuing a response;

- allowing for successive confirmations or checking the facts or checking whether hearer's disagreement stems from the misunderstanding of speaker's referencing or from some other source; giving the consequence of some event (Pomerantz 1984b:152-165);

- modifying one's position called a self-qualification (Mori 1999). 


\section{Listener's signals, some examples}

- expressives or exclaims through which emotions are displayed, amusement, approval are expressed such as: oh, laughter, applause (Heritage 1984:299-346; House 1982);

- signals of continued attention such as: yes, uh-huh, yeah, I see, good, applause (Heritage 1984:299-346);

- continuers or go - ons such as passive $m h m$ or aha with rising intonation or active continuers yes, right which avoid or defer treating the former talk as informative, well indicating listener's readiness to take over the speaking turn; yes or $\mathrm{mhm}$ as passive continuation object when oh would be inappropriate (Pomerantz 1984b:152165; Schegloff 1984:28-53; Heritage 1984:299-346; House 1982);

- displays of understanding such as $o h+$ the turn, oh + partial repeats (Heritage 1984);

- floor holders uh; eh::m (Jefferson 1984:191-223);

- summaries or reviews. These can also appear as speaker's signals; summary assessments implicating the closure of the topic (Jefferson 1984:191-223; Schegloff 1984:28-53);

- understanding checks - identifying a problem in the previous tum's talk by proposing a solution to that trouble (Jefferson 1984:191-223);

- checks/requests for a repair such as: you really think so?, can you repeat that? (House 1982; Button and Casey 1984:167-191);

- asides giving the information about the side activity let me think (House 1982).

\section{Speaker's signals}

- clarifiers, checking common knowledge such as: so (Schegloff 1984:28-53; House 1982);

- cajolers used to enhance the harmony between participants in the interaction: I think, you know, really, I mean (House 1982);

- underscorers emphasizing the discussed matter: see, you see, the problem is, the point is, the thing is, the problem is, look (House 1982).

\subsection{Reciprocity in Agreements and Disagreements}

The discussion analyzed here is one of the final ones in a series of similar discussions conducted during the year and aimed at improving learner's control of dialogic signals and practicing argumentation while maintaining engaged reciprocity and developing discursive independence ${ }^{2}$. For the purpose of the debate, learners divided themselves into two opposing debate groups arguing for or against the existence of alien life forms. Such discussion design indicated certain preallocation

\footnotetext{
${ }^{2}$ The research has been conducted in the Department of Glottodidactics and Translation Studies at the University of Adam Mickiewicz in Poznan in 2000/2001; participants were the third year students of this department.
} 
of turn types in a simulation of the social and cognitive conflict. The main research questions concerning the effectiveness of the above mentioned technique were the following:

- How will assuming different social and interactional roles to create the social and cognitive conflict influence the interactivity and the recipient design of school discussions?

- How will learners develop control of the interaction in argumentative discussions while construing the social and cognitive conflict? How will their independence develop with respect to the construction of arguments and maintaining contact with interlocutors in the specific design of a social and cognitive conflict?

The interactive roles of learners during the year gradually evolved into more engaged and independent ones. This may have taken place as a result of the change of the participation framework design and thanks to self-reflective tasks of evaluating one's own and other participants' moves during classroom discussions as well as in the course of a series of tasks of the evaluating observations of TV discussions in a native and a foreign language ${ }^{3}$.

One of the main challenges for learners proved to be developing interactive competence, understood as construing disagreements and maintaining contact without antagonizing the recipient. Another significant interactive and argumentative skill was maintaining contact with both opponents and supporters; speakers realized those roles in various types of interactional moves, the main ones being piggybacking and evaluating reformulations.

Piggybacking was selected for the analysis in this paper because it is one of the more important moves by which speakers organize their multiparty discussions. Whereas, using evaluating reformulations, participants control their coparticipants' personal engagement and simultaneously and explicitly show the cognitive control of the ongoing discussion, the moves reserved for teachers in more teacher-fronted contexts.

\subsubsection{Indirectness as a way of maintaining reciprocity}

Recipient oriented mitigating signals in argumentative claims which appear in the classroom discussion show speakers' orientations to both construing arguments and maintaining contact with the partner. Another aspect of argumentative discussions is its multiparty character. Because speakers act within a multiparty participation framework their actions often have to orient to multiple recipients at the same time. Goodwin (1995:198-219) claims that the ability of incorporating more than one speaker in the construction of the speaking turn is one of the basic com-

${ }^{3}$ The analysis of learners' self-evaluation and monitoring techniques is not the main subject of this paper and will appear in the report from the group project. See W. Wilczyńska 2001. 
ponents of interactional competence in one's native language. Let us look at this double focus of speakers' actions using an extract from a classroom discussion.

\subsubsection{Piggybacking}

The Goodwins claim that piggybacking constitutes a specific kind of an interactional move appearing in multiparty argumentations. It is a type of an alignment structure and social organization that can be invoked within an oppositional move. Piggybacking allows a third party to participate in the exchange by inserting actions in between the two-party exchange. For example, the speaker, Chopper in line 2, and Bruce in line 4 perform piggybacking:

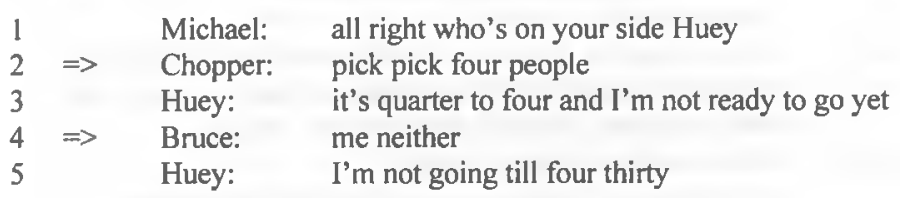

Michael's actions create relevance for Huey's answers while inserted piggybacking moves are parasitic in nature since their absence wouldn't disrupt the sequence (Goodwin and Goodwin 1990:101-117).

Speakers use piggybacking in multi-party arguments to perform two actions, affiliation and opposition directed at two parties in a conversation at the same time or they resort to piggybacking to oppose both speakers and establish their independence, as happened in the discussion about UFO's. All the analyzed extracts below come from a discussion about the existence of aliens. Prior to extract 1, speakers discussed the possibility of finding evidence for the existence of aliens. $\mathrm{AS}, \mathrm{PB}$ and $\mathrm{AK}$ belong to the group of debaters arguing for the existence of aliens while $\mathrm{Z}$ and MF oppose them. $\mathrm{N}$ stands for a teacher, $\mathrm{S}$ for an unidentified student and Ss for a group of students.

\section{Extract 1}

\begin{tabular}{|c|c|c|c|}
\hline \multirow{9}{*}{$\rightarrow$} & 45. & PB & we can just check it(.)in internet= \\
\hline & 46. & AS & $=$ check it in internet ehhh \\
\hline & 47. & S & No if you say so(.)as it shows $(\mathrm{xxx})()$. \\
\hline & 48. & $\mathrm{EZ}$ & (it must you know)(...) \\
\hline & 49. & PB & we are not prepared right now \\
\hline & 50. & $\mathbf{S}$ & Ehhh \\
\hline & 51. & $\mathrm{Z}$ & so:: \\
\hline & 52. & PB & $\begin{array}{l}\text { but we've just heard about it(.)and we've read about it(.)and } \\
\text { we can assume }=\end{array}$ \\
\hline & 54. & $\mathrm{EZ}$ & $=($ really $)(.) I^{\prime} v e$ never heard about it $()$. \\
\hline
\end{tabular}




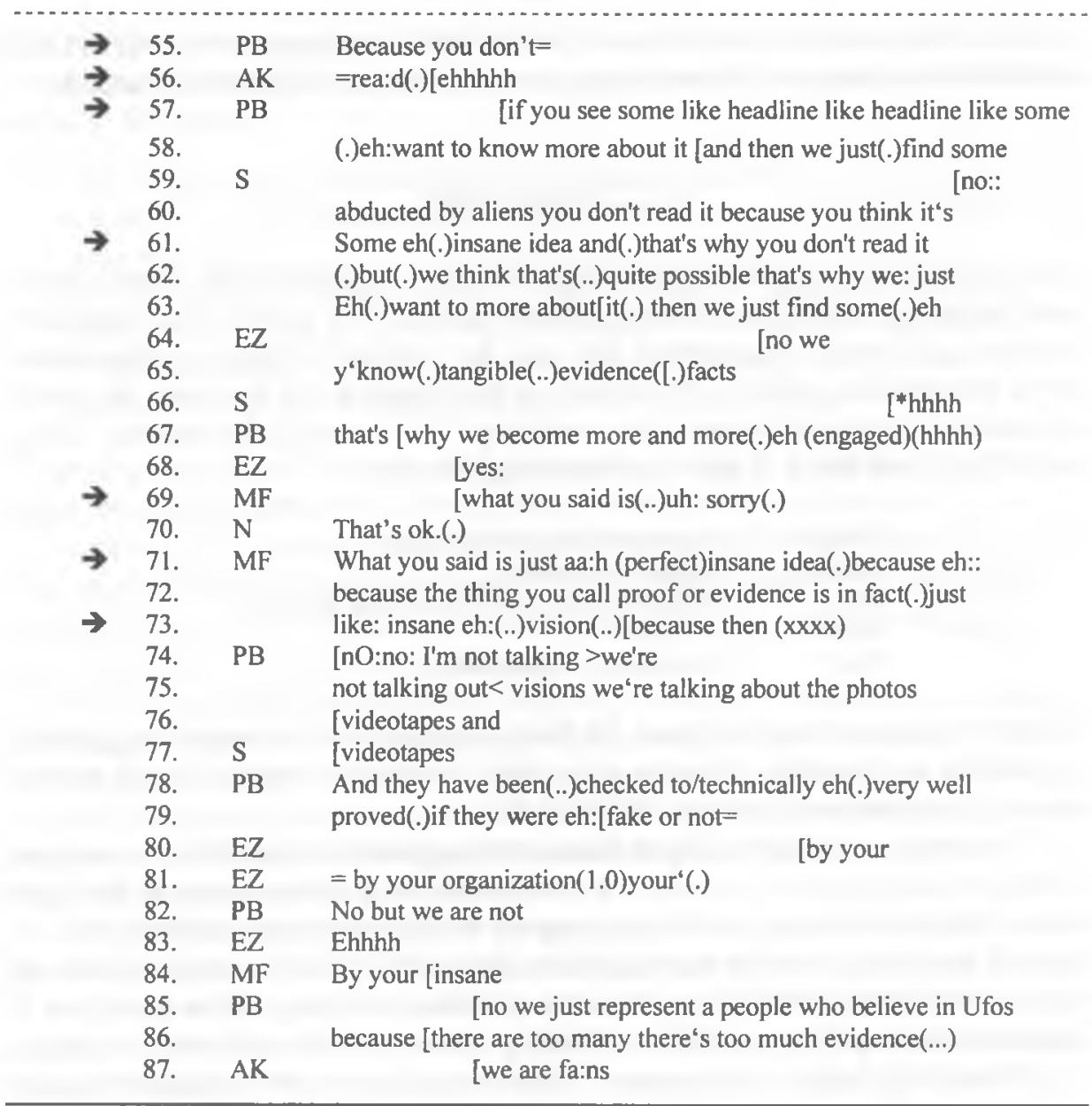

AS in one turn (46) manages to perform two simultaneous actions at the same time. She aligns with PB's actions by using partial repetition or echoing and at the same time she opposes $\mathrm{Z}$ softening her utterance by adding laughter at the end of the turn. AS uses less intrusive piggybacking allowing the supported party to continue.

Piggybacking also seems to occur as humorous finishing of the first party turns as it happens in segment (56). Finishing the oppositional statements for another seems to be a more intrusive signal that in this case introduces a competitive interpretation of Z's actions. Such sequential position, the third party intrusion, also allows for greater directness since it appears as only an optional possibility that can be reformulated or elaborated on by the first speaker as happens in (57).

Additionally, the inserted third party commentary can be either accepted or rejected by the first party, as it happens in the extract 2 below: 


\section{Extract 2}

\begin{tabular}{|c|c|c|c|}
\hline & 158. & MF & {$[\mathrm{xxxxxxx}$} \\
\hline & 159. & & Gorillas[because they were(.)just made up \\
\hline & 160. & $\mathbf{S}$ & {$\left[{ }^{*} \mathrm{ehhhh}^{*}\right.$} \\
\hline \multirow[t]{2}{*}{$\rightarrow$} & 161. & $\mathrm{~N}$ & *that's $\operatorname{good}^{*}(\ldots)$ \\
\hline & $\begin{array}{l}162 . \\
163 .\end{array}$ & AS & $\begin{array}{l}\text { and then:(.)they found out out that gorillas exist they are } \\
\text { no:rmal animals }\end{array}$ \\
\hline \multirow[t]{7}{*}{$\rightarrow$} & 164. & PB & hhh: \\
\hline & 165. & AS & Hhhh and(hhh)this is a fact \\
\hline & 166. & PB & hehh(..) \\
\hline & 167. & & but nobody believed in that because nobody were/went there and \\
\hline & 168. & & saw them(.) \\
\hline & 169. & MF & and the gorillas didn't get from(..) from you(.) \\
\hline & 170. & AS & ok and [you know now that the:: \\
\hline$\rightarrow$ & 171. & PB & [but you believe in jesus eh: eh[: or maria or \\
\hline \multirow[t]{5}{*}{$\rightarrow$} & 172. & AS & [no: it's not the \\
\hline & 173. & & case(.)but the universe exists(.)it is a fact and ehhh so:: and \\
\hline & 174. & & so: the $\mathrm{m} / \mathrm{arfican}($.$) forest existed(.)but(.)nobody went there$ \\
\hline & 175. & & to: saw if there are(.)gorillas(..)if you understand my point \\
\hline & 176. & AK & Mmhhhh(.) \\
\hline
\end{tabular}

Expressive, news receipting piggybacking moves. The first piggybacking move in the sequence occurs in N's (teacher's) turn in (161) and it starts the whole piggybacking sequence; that's a supportive and expressive move that directly evaluates the first party turn; it is directed at both AS and her intended recipients. AS accepts the insertion by making a relatively long pause allowing for possible elaboration on the part of N. Another aligning and expressive piggybacking is PB's laughter, which is also acknowledged by AS as she sounds out the final components of her turn with laughter. Finally, in line (176), AK produces another piggybacking continuer. Expressive supporters' signals appear quite early in the sequence when the message first appears in the discussion.

Then, even after a series of AS turns introducing and reformulating the new argument, the main recipient of the new argument, $\mathrm{MF}$, failed to respond in a complete and understandable form that would be accepted by AS. That is why after the second reformulation in line (172) AS overtly rejects PB's piggybacking contribution and evaluates it as an invalid elaboration. In the same turn she explicitly elicits from MF the specific responsive confirmation of understanding. Confirmation check is a self-initiated repair move since MF does not provide any verbal listening cues.

\subsubsection{Personalized evaluating reformulations}

Evaluating reformulations are inextricably bound with processes of social categorization. The evaluating reformulation starts with MF's $(69,71)$ in extract 1 using 
the personal pronoun you. The use of this pronoun in evaluations is a highly sensitive issue because it directly points to the agency of actions which undergo negative evaluation. Participants realize their reformulations in such a direct way that they are often close to evaluating their co-debaters as persons themselves. This feature of reformulations appearing in the context of Polish discussions seems to differ from reformulations realized in a more neutral and indirect fashion in an Anglo-Saxon context. However, MF displays an orientation to the dispreference of her action since she uses delays such as "ah::" and pauses as well as modifiers inserted after a pause plus a hesitation marker "eh:" such as "in fact (...) eh:: insane." In fact, she prefaces the potentially pejorative adjective "insane" with hesitation markers in both (61) and (73). Thus she somehow orients to the sensitive nature of her reformulation and manages to decrease the face threatening impact of her evaluation.

Evaluating reformulations with the use of you seem to influence the course of the interaction in a double way. First, they emotionally engage the recipient and second they initiate the negotiation of interactional and social statuses. They intensify the message offering the alternative and personal interpretation of speaker's message and consequently they manage to engage the speaker and evoke emotional reaction as in (74) where the response latches with the ending of the evaluation.

PB takes over the floor, quickly repeating the short negation, stretching the sound and speeding up the production of the rest of his utterance. At first he uses the personal pronoun $I$ indicating greater personal engagement and then he quickly switches to more neutral and less risky we. The addressed party PB manages to downgrade the categorization by the use of "just + the neutral category definer" referring to himself as a part of the organization "who just represent(s) people who believe in UFO's."

In fact, in the evaluating reformulation, participants display an overt orientation to the negotiation of statuses or membership categories. In this case, the negative evaluation is realized as defining the other party's actions as irrational and illogical and perhaps also implicitly manipulative. PB uses the repair sequence offering a different qualification of his previous actions during which unfavorable definition of personal "insane visions" changes into more socially acceptable "evidence" or "photos and videotapes." PB opposes MF's trials to categorize the opposing team as possibly sectarian and irrational visionaries. He aims at negotiating his position as a more rational and socially justifiable one, that is why he redefines the object of the discussion from personal you to we and next to they marking the external reference or witnesses who claim to have seen UFO's. As a result of his and AS's cooperative actions they manage to re-negotiate the object of the discussion away from the directly personal reference. 


\subsubsection{Turn final so and because}

\section{Extract 3}

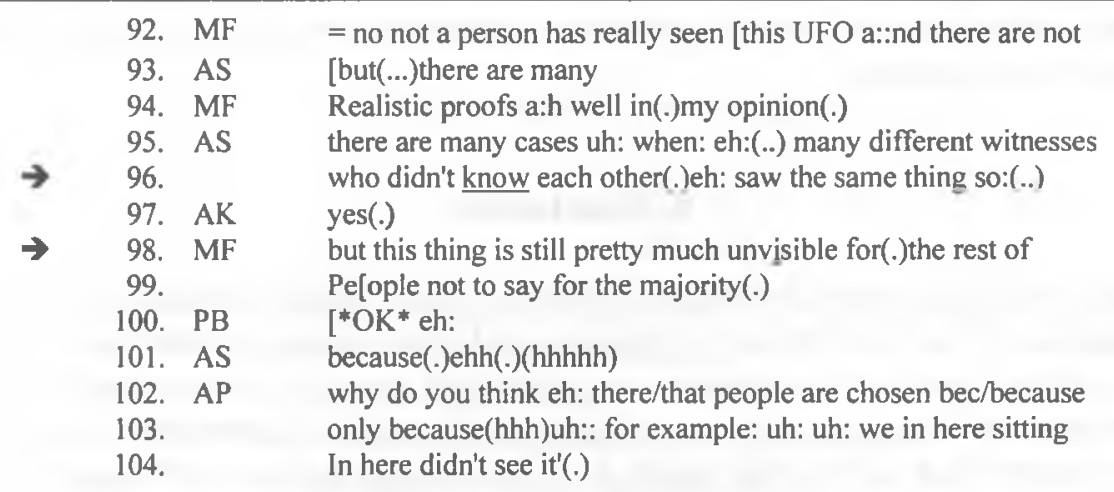

\section{Extract 4}

$\begin{array}{lll}\text { 116. } & \text { MF } & \text { they don't claim that on on the basis of this proofs and this } \\ \text { 117. } & \text { evidences we cannot claim(.)that eh: if you(.)you:(in say so)= } \\ \text { 118. } & \text { PB } & \text { =h: you can claim everything(..) so(...)uh::: } \\ 119 . & \text { Si } & \text { Eh[hhhhh } \\ \text { 120. } & \text { MF } & \text { [(xx) sceintific scientific research don't do the subject } \\ 121 . & \text { a:hm and for the point o:f view (.)of being a: scientist you } \\ 122 . & \text { just eh: cannot say tha:t eh: UFO UFO exist(.)because ehm(.) } \\ \text { 123. } & \text { [you dOn't hAve strict proofs and researches= }\end{array}$

Generally one can observe in the exerpts above that speakers use turn final so and because as a way of maintaining interactivity by inviting interruptions. Using these signals, speakers aim at a cooperative construction of arguments, and they open up a possibility for the recipient to take a turn. For example, in excerpt 3 , AS (96) ends her statement with so and a pause. In doing so she invites the recipient to react and signals that she expects collaborative interruption. At the same time she manages to mitigate the definite character of her statement projecting her utterance as possibly incomplete and open to negotiation. This is also a way of mitigating disagreement that often appears in lengthy pauses between debaters' turns. AS triggers a compatible mitigating action on the part of MF (98), who modifies her statement with "pretty much". This response in turn constitutes a self-qualification defined by Mori as a way of gaining recipient's approval.

PB uses turn final so for the same purpose of mitigating his definite stance and allowing for possible reactions realized cooperatively by a recipient. In (120) MF's opening "because uh(.)" is received by AS with a cooperative continuer 
prompt of "and why" realized with a face sensitive rising intonation pattern and eliciting MF's elaboration or justification.

Concluding from those short and preliminary observations, one can say that those signals seem to function as opening the Transition Relevance Places for second parties and they reveal participants' orientation to the cooperative construction of arguments.

\section{Conclusion}

In conclusion one important research constraint has to be acknowledged. Namely, the analysis of the development of interactional competence is limited to the specific task of argumentative discussions organized around a controversial thesis. Participants in these discussions were assuming the roles of opponents, supporters or evaluators, that is why the results to a great extent depend on this particular task context. As the Conversational Analysis method is used for research, the immediate sequential context of participants' utterances is taken into account. In this paper the analysis is limited to a sample from only one of the last discussions in a cycle.

Learners gradually developed the skills necessary for construing the conversational argumentative genre in polarized argumentative discussions, although the results remain individualized to a large extent. The conversational aspect of maintaining contact and modifying one's own or one's interlocutors moves proved to be realized in piggybacking and evaluating reformulations as well as specific turn final appealers so and because, which showed speaker's double orientation to both maintaining contact and mitigating harsh statements. Using evaluating reformulations, participants managed to evoke personal involvement of their codebaters in order to enhance the social and cognitive conflict.

Generally, one can observe that, learners coped without the teacher and took over the moves traditionally assigned to teachers in classroom discourse. The moves discussed here were steering the discussion by evaluating and reformulating one's own and one's interlocutors utterances. The interactive roles of institutionally dependent learners evolved into the roles of more independent participants actively directing the discussion and orienting to the presence of personalized interlocutors. Mitigating ones utterances and engagement moves (evaluating reformulations) showed participants' increasing orientation to the presence of personalized recipients as opposed to a merely institutional one as was the case at the outset of the present study.

Summing up, one can observe that a significant component of developing interactional competence and learner independence in argumentation seems to be the skillful construction of the social and cognitive conflict realized in specific moves and signals, some of which were analyzed in this paper. The main factor 
stimulating the construction of such conflict and increasing learner independence appears to be the participation framework of polarized argumentative discussion combined with the conscious change of social and interactional roles by learners from passive and distanced ones to socially and emotionally engaged ones.

\section{Transcription symbols used in this paper ${ }^{4}$}

\begin{tabular}{|c|c|}
\hline Symbol & Meaning \\
\hline (.) & Indicates a micropause, a pause in talk of less than one tenth of a second \\
\hline$=$ & Indicates "latching" between utterances \\
\hline 【 & Indicates the onset of overlap \\
\hline$:::$ & colons indicate the extension or stretching of sounds \\
\hline .hh & a dot before an 'h' indicates speaker in-breath \\
\hline $\mathbf{H}$ & speaker outbreath or laughter \\
\hline (h) & Indicates insertion of a laughter particle into a word during its production \\
\hline Heh & Laughter \\
\hline (1.0) & Indicates the length of pauses in talk (in seconds) \\
\hline() & $\begin{array}{l}\text { empty round brackets indicate the presence of an unclear fragment on the } \\
\text { tape }\end{array}$ \\
\hline (guess) & $\begin{array}{l}\text { the words within a single bracket indicate the transcriber's best guess at an } \\
\text { unclear utterance }\end{array}$ \\
\hline $\mathbf{A}$ & underlined fragments indicate speaker emphasis \\
\hline CAPITALS & capitals indicate increased volume relative to surrounding talk \\
\hline$* *$ & an asterix indicates decreased volume relative to the surrounding talk \\
\hline ‘ & an apostrophe indicates a marked rising intonation \\
\hline , & a coma indicates a marked falling intonation \\
\hline$><$ & $\begin{array}{l}\text { more than" and "less than" signs indicate that the talk they encompass was } \\
\text { produced noticeably quicker than the surrounding talk }\end{array}$ \\
\hline PB & Indicates speaker's initials \\
\hline $\mathbf{N}$ & letter $\mathrm{n}$ indicates a teacher \\
\hline $\mathbf{S}$ & letter $s$ indicates unidentified speaker \\
\hline
\end{tabular}

\section{REFERENCES}

Atkinson, M.; Heritage, J. (eds.) (1984): Structures of Social Action. Studies in conversation Analysis. Cambridge: CUP.

Basturkmen, H. (1998): Aspects of Impoverished Discourse in Academic Speaking: Implications for Pedagogy form a Mini-Corpus. Asian Journal of English Language Teaching Vol. 8, 81-91.

\footnotetext{
${ }^{4}$ Adapted from Smith 2000.
} 
Button, G.; Casey. N. (eds.) (1984): Generating topic: the use of topic initial elicitors. In: M. Atkinson \& J. Heritage (eds.): Structures of Social Action. Studies in Conversation Analysis. Cambridge: CUP, 167-191.

Goodwin, C.; Goodwin M.J. (1990): Interstitial Argument. In: A. Grimshaw (ed.), 83-117.

Górecka, J.; Nowicka, A. (2001): Rozwijanie autokontroli nad strategiami dyskursywnymi w interakcjach nacechowanych emocjonalnie u zaawansowanych studentów języka obcego. Neofilolog 20, 45-51.

Grimshaw, A. (ed.) (1990): Conflict Talk. Sociolinguistic Investigations of Arguments in Conversations. Cambridge: CUP.

Gülisch, E.; Kotschi, T. (1995): Discourse Production in Oral Communication. A Study Based on French. In: U. Quasthoff (ed.), 30-66.

Heritage, J. (1984): A change-of-state token and aspects of its sequential placement. In: M. Atkinson \& J. Heritage (eds.), 299-346.

House, J. (1982): Gambits in deutschen und englischen Alltagsdialogen. Versuch einer pragmatischkontrastiven Analyse. In: N. Denison; K. Sorning; H.P. Gadler; H. Grasseger, Perlokutionare Aspekte. Grazer Linguistische Studien 17/18, 110-121.

Hutchby, J; Woofit, R. (1998): Conversation Analysis. Oxford: Polity Press.

Jefferson, G. (1984): On stepwise transition from talk about trouble to inappropriately nextpositioned matters. In: M. Atkinson \& J. Heritage (eds.), 191-223.

Markee, N. (2000): Conversation Analysis. Mahwah, New Jersey and London: Lawrence Erlbaum Associates, Publishers.

Mori, J. (1999): Well I may be Exaggerating But..: Self-Qualifying Clauses in Negotiation of Opinions Among Japanese Speakers. Human Studies 22, 447-473.

Pomerantz, A. (1984a): Agreeing and disagreeing with assessments: some features of preferred/dispreferred turn shapes. In: M. Atkinson \& J. Heritage (eds.), 57-102.

Pomerantz, A. (1984b): Pursuing a response. In: M. Atkinson \& J. Heritage (eds.), 152-165.

Prokop, I. (1995): Erotetische Sprechakte im Deutschen und im Polnischen anhand natürlicher Gespräche. Poznań: Wydawnictwo Naukowe UAM.

Prokop, I. (2001): Typy interakcji w dydaktyce. Neofilolog 20, 13-22.

Quasthoff, U. (ed.) (1995): Aspects of Oral Communication. Berlin: Walter de Gruyter.

Quasthoff, U. (1995): Orality and ontogenesis: towards the interactive constitution of linguistic development. In: U. Quasthoff (ed.), 257-279.

Sacks, H. (1984): Notes on methodology. In: M. Atkinson \& J. Heritage (eds.), 21-28.

Schegloff, E.A. (1984): On some questions and ambiguities in conversation. In: Atkinson M. \& J. Heritage (ed.), 28-53.

Seedhouse, P. (1996): Learning Talk: A Study of the Interactional Organization of the L2 Classroom from a CA Institutional Discourse Perspective. Unpublished Ph.D. Dissertation.

Silverman, D. (1998): Harvey Sacks. Social Science and Conversation Analysis. Cambridge: Polity Press.

Smith, C. (2000): Facilitating 'Persepectival Reciprocity' in Mediation: Some reflections on a Failed Case. Human Studies 23, 1-21.

Wilczyńska, W. (1999): Uczyć się czy być nauczanym? O autonomii w przyswajaniu języka obcego. Warszawa: PWN.

Wilczyńska, W. (2001): Autonomizacja jako przedmiot badań glottodydaktycznych. Neofilolog 20, 6-12.

Wilczyńska, W. (ed.) (2002): Doskonalenie się w komunikacji ustnej. Autonomizacja studentów a efektywność dydaktyki języków obcych. Poznan: Wydawnictwo Naukowe UAM. 